\title{
DIREITO TRIBUTÁRIO, COMPLEXIDADE E ANÁLISE ECONÔMICA DO DIREITO
}

\author{
TAX LAW, COMPLEXITY AND LAW AND ECONOMICS
}

\author{
ANDRÉ FOLLONI \\ Professor do Programa de Pós-Graduação em Direito do Mestrado e Doutorado da \\ Pontifícia Universidade Católica do Paraná (PUC/PR). \\ andrefolloni@gmail.com \\ CAMILA Beatriz Simm \\ Mestranda em Direito Econômico e Desenvolvimento da \\ Pontifícia Universidade Católica do Paraná (PUC/PR). \\ camila_simm@yahoo.com.br
}

\section{RESUMO}

O estudo critica o modelo reducionista que prevalece na doutrina tributarista. Os esforços da doutrina concentram-se no estudo meramente estrutural e semântico das normas tributárias, ignorando outras variáveis importantes, como os efeitos econômicos que provoca. O Direito Tributário é um sistema complexo que interage com outros sistemas sociais, como o econômico, e essas interações precisam de ser examinadas pela doutrina. Atento à necessidade de desenvolvimento dos estudos jurídicos tributários, o trabalho defende a construção de uma ciência do Direito Tributário complexa, o que demanda, dentre outras providências, estudos interdisciplinares. A Análise Econômica do Direito apresenta-se como uma ferramenta importante no caminho para o desenvolvimento de uma ciência complexa do Direito Tributário. Algumas aplicações da Análise Econômica do Direito ao Direito Tributário são expostas no artigo, mostrando suas potencialidades, sem esconder seus limites, cumprindo assim o objetivo do texto. 0 artigo adota, como método, a interdisciplinaridade e concentra a sua pesquisa em material bibliográfico.

Palavras-chave: Análise Econômica do Direito; Tributação; Complexidade; Interdisciplinaridade; Desenvolvimento.

\begin{abstract}
The study criticizes the reductionist model of Science that preponderates among Tax Law scholars, whose efforts are exclusively focused on the structural and semantic studies of tax rules. Other important variables such as the economical effects of the rules are ignored. Tax Law is a complex system that interacts with other social systems, like the economical, and these interactions must be examined by the scholars. Regardful to the need of development in the tax legal studies, this work endorses the construction of a complex Tax Law Science, which demands interdisciplinary studies among other needs. Law and Economics appears as an important tool in the way of development of a complex Tax Law Science. The article exposes some applications of Law and Economics to Tax Law, showing its potential without hiding its limits, then meeting the objective of the paper. The article adopts interdisciplinary as a method and focuses its research in bibliographical material.
\end{abstract}

Keywords: Law and Economics; Taxation; Complexity; Interdisciplinary; Development 


\section{(1)

\section{SUMÁRIO}

INTRODUÇAO; 1. CIÊNCIA DO DIREITO TRIBUTÁRIO ATUAL; 2. DIREITO TRIBUTÁRIO SOB A PERSPECTIVA DA COMPLEXIDADE; 3. ANÁLISE ECONÔMICA DO DIREITO: LINHAS GERAIS; 4. ANÁLISE ECONÔMICA DO DIREITO APLICADA AO DIREITO TRIBUTÁRIO; 4. 1. Questões tributárias suscetíveis de exame à luz da AED; 4. 1. 1 Obrigações acessórias; 4. 1. 2 Incentivos fiscais; 5. ANÁLISE ECONÔMICA DO DIREITO: LIMITES E POSSIBILIDADES PARA A CONSTRUÇÃO DE UMA CIÊNCIA COMPLEXA; CONCLUSÃO; REFERÊNCIAS.

\section{INTRODUÇÃO}

A doutrina do Direito Tributário, no Brasil, comumente recebe críticas em razão da sua insuficiente conexão com a realidade socioeconômica na qual está inserida. Isso implicaria, dentre outros problemas, um importante défice de utilidade. Meros exames descritivos, tendo por base enunciados prescritivos, são, em geral, insuficientes para a resolução dos complexos problemas que se apresentam ao tributarista.

De fato, o Direito Tributário não está restrito à sua própria realidade. É um sistema que se comunica e que interage com outros sistemas sociais que fazem parte de seu entorno. Essa comunicação, aliás, envolve retroação: ao mesmo tempo em que os sistemas sociais influenciam o Direito e, em especial, o Direito Tributário, o fenômeno jurídico também influencia os demais segmentos da vida social. Essas interações viabilizam o surgimento de características novas (emergências), cuja compreensão é inviável a partir do estudo de um elemento isolado, como a norma jurídica.

Parcela significativa da doutrina tributarista não assume essas questões como problemas a serem resolvidos, contentando-se com pesquisas restritas ao estudo das normas jurídicas tributárias, com pouco ou nenhum cotejo com outros aspectos que influenciam o sistema jurídico, como a economia, a política e a ética.

Diante dessas questões, este artigo propõe-se a examinar em que medida a Análise Econômica do Direito (AED), aplicada ao Direito Tributário, pode permitir o avanço na pesquisa, sob a presunção de que, sendo complexa a realidade sobre a qual se voltam os estudos jurídicotributários, complexa deve ser a ciência que a tem por objeto. Para tanto, o artigo inicia com uma breve análise de como vem se desenvolvendo a ciência do Direito Tributário no Brasil, destacando as principais críticas, bem como a inserção histórica desse modo de construir ciência. Em seguida, o estudo procura compreender em que medida uma ciência pode ser considerada como complexa e por que essa complexidade, em vez de danosa, é necessária. 
Dentre as várias características da complexidade, 0 artigo sublinha 0 viés da interdisciplinaridade: a ciência que se pretende complexa precisa estar aberta a outras áreas do conhecimento.

No âmbito do Direito Tributário, destaca-se a possibilidade de aplicação dos referenciais da Análise Econômica do Direito, a fim de enfrentar questões que demandam conhecimentos específicos da ciência econômica. Em primeiro plano, estuda-se, de forma introdutória, o que vem a ser a Análise Econômica do Direito, as suas premissas e o seu desenvolvimento. Na sequência, exemplificam-se hipóteses em que essa espécie de análise pode ser aplicada a situações que constituem o objeto preocupação dos tributaristas.

A aproximação entre Direito e Economia, como será vista adiante, está longe de esgotar todas as relações travadas com o Direito, porém viabiliza, em certa medida, a construção de uma ciência complexa.

\section{CIÊNCIA DO DIREITO TRIBUTÁRIO ATUAL}

A história do tributo é extensa, mas o Direito Tributário, enquanto campo sistematizado de disciplina e de conhecimento jurídico, é recente. O seu referencial histórico de nascimento é o Código Tributário Alemão de 1919, produzido após o final da Primeira Guerra Mundial. ${ }^{1}$

No Brasil, a doutrina do Direito Tributário demorou a desenvolver-se, tendo início, basicamente, apenas após a Segunda Guerra. Basicamente, duas razões explicam esse fato. A primeira delas refere-se à ausência, nas grades dos cursos de Direito, da disciplina de Direito Tributário. Primeiramente, ela foi ministrada nos cursos de contabilidade e administração. Mais tarde, nos anos de 1970, foram ofertadas as primeiras disciplina de Direito Tributário, na Universidade de São Paulo e na Universidade Mackenzie.

Outro motivo que contribuiu para o desenvolvimento apenas tardio da doutrina do Direito Tributário foi a falta de sistematização da matéria jurídico tributária no plano do direito positivo. Não foi à toa que grandes juristas defenderam a criação de um Código Tributário Nacional, que unificasse o tratamento da matéria tributária, que era díspar em relação à União, Estados e Municípios. Alfredo Augusto Becker traça um interessante panorama sobre os primórdios do Direito Tributário no Brasil:

\footnotetext{
${ }^{1}$ GRECO, Marco Aurélio. Crise do formalismo no direito tributário brasileiro. Revista da PGFN. 2011 , p. 2. Disponível em: http://www.pgfn.fazenda.gov.br/revista-pgfn/revista-pgfn/ano-i-numero-i/greco.pdf. Acesso em: 01jul.2015.
} 
Há 40 anos, o Sistema Tributário brasileiro era estruturado de acordo com a forma e a cor das estampilhas. Havia estampilhas federais, estaduais e municipais e as diretrizes da Política Fiscal concentravam-se em disciplinar arduamente a hierarquia dos formatos das estampilhas e a tropicalidade das suas cores. [...]. Naquele tempo, graças ao colorido e ao formato das estampilhas, o chamado Sistema Tributário era um Carnaval. Só havia confusão, muito papel colorido e era até divertido. ${ }^{2}$

Em razão das condições iniciais adversas quando do surgimento do Direito Tributário no Brasil, a doutrina tributarista concentrou-se em tentar realizar estudos descritivos do ordenamento jurídico tributário, fundada na teoria da norma tributária que já se desenvolvia na Europa. Trata-se de uma análise reducionista, voltada para o que já está feito (positivado), e fortemente preocupada com os aspectos semântico e sintático das normas. A preocupação central do estudo concentrava-se nas normas de instituição, fiscalização e arrecadação dos tributos. $^{3}$

São de notório conhecimento os estudos de Geraldo Ataliba a respeito da Hipótese de Incidência Tributária, com a análise da norma tributária nos aspectos material, temporal, espacial e pessoal: embora dividida em vários aspectos para fins didáticos, ressalta o autor, a norma permanece una e incindível. ${ }^{4}$ Por sua vez, Paulo de Barros Carvalho vislumbra a regra matriz de incidência tributária em hipótese (descrição do fato que ensejará o nascimento da relação jurídico tributária, por meio da definição dos critérios material, temporal e espacial e, excepcionalmente, subjetivo) e consequência (prescreve a relação jurídico tributária, mediante a qualificação dos critérios pessoal e quantitativo). ${ }^{5}$

Marco Aurélio Greco observa que esse modo de desenvolver a doutrina do Direito Tributário, focada no aspecto estrutural da ordem jurídica, era a mais adequada para o período histórico de ditadura militar. Os estudos, compreensivelmente, estavam fortemente centrados em aspectos formalísticos das normas jurídicas, em detrimento de aspectos de cunho substancial. Durante esse período, cabe destacar que a Emenda Constitucional n. ${ }^{\circ} 18$, de 1965,

\footnotetext{
2 BECKER, Alfredo Augusto. Carnaval Tributário. 2.ed. São Paulo: LEJUS, 1999, p. 13.

${ }^{3}$ FOLLONI, André. O papel do direito tributário no desenvolvimento nacional. In: Anais do XXIII Encontro Nacional do CONPEDI. Disponível em: http: / / www.publicadireito.com.br/artigos/?cod=20dd77ae36c56353. Acesso em: 10 set. 2014, passim. ${ }^{4}$ ATALIBA, Geraldo. Hipótese de incidência tributária. 6.ed. São Paulo: Malheiros Editores, 2013, p. 65.

${ }^{5}$ CARVALHO, Paulo de Barros. Curso de direito tributário. 25.ed. São Paulo: Editora Saraiva, 2013, p. 260 e 284 .
} 
excluiu do artigo 202 da Constituição Federal de 1946, o princípio da capacidade contributiva, de fundamental importância para averiguar o grau de justiça substancial da tributação. ${ }^{6}$

Segundo José Roberto Vieira, a análise estrutural da regra matriz de incidência tributária é o caminho científico mais confiável para compreender o tributo no seu aspecto estrutural. Essa maneira de se aproximar do objeto de estudo rendeu frutos consideráveis, haja vista que diversos trabalhos de peso em Direito Tributário seguiram esse método de estudo, com resultados importantes. ${ }^{7}$

Contudo, os méritos da perspectiva estruturalista do Direito Tributário não podem servir para ocultar certas deficiências, que têm sido apontadas, contemporaneamente, pela doutrina. 0 estudo do Direito Tributário, de fato, assumiu forte viés positivista, ao estabelecer como objeto de estudo exclusivo o direito positivo. A Ciência do Direito Tributário reduziu-se a mera aferidora da cientificidade de proposições elaboradas tendo por base o ordenamento jurídico. Ou seja, o que se busca fazer, quase exclusivamente, são testes de verificabilidade, de forma a investigar a compatibilidade factual entre enunciados descritivos com seus objetos normativos, que são os enunciados prescritivos. ${ }^{8}$

Antes mesmo de criticar esse modo de fazer ciência, propriamente dito, é interessante apontar o desvio ocorrido, pelo qual os próprios cientistas se afastaram de tal método, ao confrontarem enunciados descritivos não com o ordenamento positivo, mas com modelos ideais e platônicos. Obrigação tributária acessória, por exemplo, não seria obrigação propriamente dita, uma vez que segundo o modelo ideal, a obrigação deve sempre apresentar cunho pecuniário. Da mesma forma, seria inconcebível defender a existência de obrigação e crédito tributário surgindo em momentos distintos, pois jamais se separariam o crédito da obrigação. ${ }^{9}$

Humberto Ávila denuncia, ainda, como a doutrina jurídica vem perdendo relevância prática. Dentre as várias críticas feitas pelo jurista, uma delas diz respeito ao fato de que a doutrina, ao se restringir ao exame da veracidade ou falseabilidade dos enunciados descritivos

\footnotetext{
${ }^{6}$ GRECO, Marco Aurélio. Crise do formalismo no direito tributário brasileiro. Revista da PGFN. 2011, p. 4. Disponível em: http://www.pgfn.fazenda.gov.br/revista-pgfn/revista-pgfn/ano-i-numero-i/greco.pdf. Acesso em: 01 jul.2015.

7 VIEIRA, José Roberto. Imposto sobre Produtos Industrializados: uma águia garciamarquiana entre os tributos. In: SANTI, Eurico Marcos Diniz de; ZILVETI, Fernando Aurélio; MOSQUERA, Roberto Quiroga (coords.). Tributação das Empresas. São Paulo: Quartier Latin, 2006, p. 173.

${ }^{8}$ ÁVILA, Humberto. A doutrina e o Direito Tributário. In: ÁVILA, Humberto (org.). Fundamentos do direito tributário. Madrid: Marcial Pons, 2012, p. 224.

${ }^{9}$ FOLLONI, André. O papel do direito tributário no desenvolvimento nacional. In: Anais do XXIII Encontro Nacional do CONPEDI. Disponível em: http://www.publicadireito.com.br/artigos/?cod=20dd77ae36c56353. Acesso em: 10 set. 2014.
} 
em face do ordenamento jurídico posto, deixa de lado o exame de outras questões também importantes, tais como finalidades, efeitos, comportamentos e bens jurídicos envolvidos na tributação. $^{10}$

Outro autor que tece críticas relevantes ao modelo teórico adotado no Direito Tributário brasileiro é José Souto Maior Borges. Em seu diagnóstico, o atual cenário da doutrina do Direito Tributário reflete, em boa parte, meras trocas de opinião por opinião. Pouco se produz de novo na doutrina tributária. Os estudos em Direito Tributário estão restritos aos planos da sintática e da semântica, e ainda estão por avançar em direção à pragmática. ${ }^{11}$

E, de fato, é preciso inserir a perspectiva pragmática nos estudos do direito tributário. Isso tem razão de ser por motivos de índole constitucional, visto que o tributo se insere como elemento de um sistema maior, o Estado Democrático de Direito, cujas finalidades não se restringem à mera arrecadação de receitas aos cofres estatais. A tributação deve estar, também, orientada para a justiça social distributiva, é dizer, recolher recursos daqueles que deles dispõem para prestar serviços àqueles que necessitam. Além disso, a exação deve cumprir o relevante papel de induzir comportamentos mediante a extrafiscalidade. ${ }^{12}$

Cada vez mais é preciso que o tributo seja examinado em seu aspecto funcional, pois deve contribuir para o alcance dos objetivos constitucionais da República Federativa do Brasil, como a construção de uma sociedade livre, justa e solidária. ${ }^{13} \mathrm{E}$, para tal desiderato, uma ciência do Direito Tributário restrita aos aspectos formais da norma tributária pouco auxiliará para o atendimento do projeto de futuro previsto na Constituição.

\section{DIREITO TRIBUTÁRIO SOB A PERSPECTIVA DA COMPLEXIDADE}

A doutrina do Direito Tributário no Brasil, então, restringiu os seus esforços para o estudo das normas instituidoras, fiscalizadoras e arrecadadoras de tributos. É uma ciência que se desenvolve com pretensões de cientificidade e universalidade. Isso porque caberia à ciência o

\footnotetext{
${ }^{10}$ ÁVILA, Humberto. op. cit., p. 224.

11 BORGES, José Souto Maior. Um ensaio interdisciplinar em Direito Tributário: superação da dogmática. Revista Dialética de Direito Tributário. São Paulo: n. 211, p. 106-121, abril/2013, p. 107.

12 MOREIRA, André Mendes; MACHADO, Sophia Goreti Rocha. Conceito de tributo e sua divisão em espécies. In: GRUPENMACHER, Betina Treiger (coord.). Tributação: democracia e liberdade: em homenagem à Ministra Denise Martins Arruda. São Paulo: Noeses, 2014, p. 13.

${ }^{13}$ GRECO, Marco Aurélio. Crise do formalismo no direito tributário brasileiro. Revista da PGFN. 2011, p. 5. Disponível em: http://www.pgfn.fazenda.gov.br/revista-pgfn/revista-pgfn/ano-i-numero-i/greco.pdf. Acesso em: 01jul.2015.
} 
papel de aferir a cientificidade de enunciados descritivos com base nos enunciados prescritivos existentes. Contudo, essa empreitada conduz à pouca utilidade da doutrina para a resolução de muitos dos problemas que a ela são apresentados.

Nesse sentido, é inconcebível aceitar a desconsideração de problemas apenas porque determinada forma de se fazer ciência, por hipótese adotada, não teria condições de os enfrentar adequadamente. Não cabe ao jurista considerar como sendo um falso problema aquele que não é resolvido por seu estudo eventualmente redutor. ${ }^{14}$ Como ensina Humberto Ávila, a doutrina não pode ser um seletor de problemas. Ao contrário, ela deve enfrentá-los, bem como encarar as complexidades, em vez de ignorar os problemas na tentativa de reduzi-los. ${ }^{15}$

O Direito Tributário, ao restringir o seu objeto de estudo à norma tributária (regras referentes à arrecadação, instituição e fiscalização de tributos), deixou de dar atenção a diversos aspectos importantes. Em primeiro lugar, cabe destacar que o corte metodológico adotado, qual seja, a norma tributária, por si só já exclui diversas outras normas integrantes do ordenamento jurídico, como as regras relativas à administração tributária, processo tributário e assim por diante.

Mais além, o estudo restrito à norma tributária ignora a perspectiva de que o sistema jurídico influencia seu entorno, ao mesmo tempo em que é influenciado pelo meio em que se insere. As implicações sociais, econômicas e ambientais que as normas tributárias exercem no meio (outputs), as manifestações que o meio imprime ao direito tributário (inputs), bem como as significações que decorrem dessas interações não são captadas pelos estudos. Disso decorre que a doutrina concentrada na análise da norma posta deixa de lado a própria realidade empírica sobre a qual se deveria debruçar. ${ }^{16}$

No contexto maior das propostas científicas redutoras, do qual o Direito Tributário poderia ser um exemplo, Edgar Morin faz um convite para desenvolver um pensamento complexo. 0 que se pretende, em síntese, seria combater o pensamento mutilante e promover uma espécie de conhecimento que abarcasse em si diversas perspectivas: um conhecimento multidimensional. É por isso que a complexidade, segundo o estudioso, carrega uma perspectiva positiva ou progressiva e negativa ou regressiva, simultaneamente, de forma paradoxal. 0 viés negativo ou regressivo mostra-se na medida em que se reintroduz a ideia de incerteza, em

\footnotetext{
${ }^{14}$ FOLLONI, André. Reflexões sobre complexity science no direito tributário. In: MACEI, Demetrius Nichele et. al. (coord.). Direito tributário e filosofia. Curitiba: Instituto Memória, 2014, p. 77.

${ }_{15}$ ÁVILA, Humberto. A doutrina e o Direito Tributário. In: ÁVILA, Humberto (org.). Fundamentos do direito tributário. Madrid: Marcial Pons, 2012, p. 233.

${ }^{16}$ FOLLONI, André. op. cit., p. 25.
} 
contraposição ao tão almejado ideal de certeza científica absoluta. Por sua vez, a perspectiva positiva ou progressiva consiste na adoção do pensamento multidimensional. ${ }^{17}$

Complexidade, originariamente, pode significar, dentre outras coisas, tudo aquilo que está entrelaçado, tecido em conjunto. Pensar na complexidade é pensar sobre a complexidade do mundo real, com as dinâmicas presentes no mundo real. Pensar na complexidade depende, por isso, de se superar o pensamento meramente linear em direção a um pensamento em rede ou em teia. Complexidade não é apenas o resultado do entrelaçamento, mas sim o processo desse entrelaçamento, que conduz a efeitos inesperados e não-lineares. ${ }^{18}$

Portanto, complexidade não pode ser confundida com dificuldade, mas refere-se a conjuntos de elementos heterogêneos em constante interação. Essas interações são responsáveis pelo aparecimento de emergências, padrões que surgem das interações e que não são redutíveis à soma das partes. Por isso, ao tratar sobre complexidade, David Byrne prontamente adverte:

"No entanto, uma das vantagens desta aproximação é precisamente a sua rejeição acerca da validade das estratégias analíticas, as quais consideram que as coisas são reduzíveis à soma de suas partes". ${ }^{19}$

A complexidade tem por marca o aparecimento de emergências, as quais, como já se disse, resultam das interações entre as partes de um sistema complexo e delas com o ambiente em que o sistema se insere, mas que não são redutíveis à soma de seus elementos constitutivos. As emergências surgem nos mais diversos sistemas complexos, embora guardem certas características comuns. Elas relacionam-se a algo novo, não redutível aos elementos, observáveis no nível macro. Além da novidade e nível macro de aparecimento, as emergências traduzem uma certa coerência e coesão, na medida em que aproximam as partes do todo. Ademais, são vislumbradas no momento em que se revelam, assim como se mostram dinâmicas, pois alteram-se, inclusive quando os elementos que as formam se modificam. ${ }^{20}$ É preciso destacar que as interações travadas entre as partes podem conduzir a resultados não previstos,

\footnotetext{
17 MORIN, Edgar. O desafio da complexidade. In: Ciência com consciência. Tradução de Maria $D$. Alexandre e Maria Alice Sampaio Dória. Rio de Janeiro: Bertrand Brasil, 1996, p. 175-193, p. 188.

18 JÖRG, Ton. New thinking in complexity for the social sciences and humanities: a generative, transdisciplinary approach. New York: Springer, 2011, p. 43-84, p. 45.

${ }^{19}$ Tradução livre de: "However, one of the most important things about the approach is precisely its rejection of the validity of analytical strategies in which things are reducible to the sum of their parts" (BYRNE, David. Complexity Theory and the Social Sciences: an introduction. London: Routledge 1998, p.14).

${ }^{20}$ GOLDSTEIN, Jeffrey. Emergence as a construct: history and issues. Emergence. v. 1, n. 1, p. 49-77, 1999 , p. 50.
} 
não por uma causa, mas por diversas causas, as quais não se coadunam com a simples soma das partes em causalidade simples linear. ${ }^{21}$

Em relação ao Direito Tributário, é possível exemplificar o ponto com a questão da extrafiscalidade. 0 aumento ou a redução de alíquotas de tributos, com o fito de modificar comportamentos nem sempre alcança os objetivos almejados pelo Estado. É significativo o caso de aumento do Imposto sobre Operações de Crédito para as operações financeiras efetuadas fora do Brasil com cartão de crédito. Mesmo com o aumento da tributação sobre tais operações, as compras efetuadas por brasileiros no exterior continuaram altas. ${ }^{22}$ Outras causas, para além do aumento do imposto, influenciaram no comportamento dos turistas brasileiros. Ou seja, não há causalidade automática entre aumento do tributo e desincentivo eficaz do comportamento.

Nessa linha, é cristalina a compreensão de que uma ciência redutora será incapaz de explicar muitos fenômenos não lineares como esse. 0 entendimento de que o Direito é um sistema em constante interação com outros sistemas exige que a doutrina assuma um viés interdisciplinar. Não se quer, por óbvio, negar a importância do estudo das normas jurídicas, mas destacar que a norma é apenas mais um elemento presente no sistema jurídico, ao lado de outros, e a sua exclusividade como objeto não pode obstar o desenvolvimento científico. ${ }^{23}$

Ademais, importa esclarecer que a complexidade não se confunde com completude. A complexidade, ao contrário, reconhece a incompletude do conhecimento. Edgar Morin ${ }^{24}$ explica que as ciências humanas e sociais sem a visão de complexidade separam a realidade em aspectos que não se comunicam: econômico, social, ético, psicológico e assim por diante. E essas separações são compreendidas como reflexo da realidade. Ignora-se, porém, que, na esfera econômica, aparecem sentimentos humanos, por exemplo. A compreensão econômica, portanto, não está isolada de outras dimensões. A complexidade, dessa forma, reconhece a perspectiva multidimensional do conhecimento. Esse reconhecimento conduz à conclusão de que jamais será possível desconectar-se totalmente da incerteza, bem como obter um saber completo. É preciso admitir essa incompletude ingênita e aprender a trabalhar com ela.

Da mesma forma, complexidade não visa a um saber holístico em que se procede a um sincretismo metodológico. Não se pretende extinguir fronteiras existentes nos campos de cada

\footnotetext{
${ }^{21}$ BYRNE, David. op. cit., p. 20.

${ }^{22}$ MARTELLO, Alexandro. G1. Brasília, 06 mar. 2012. Gastos com cartão de crédito em reais no exterior têm IOF de 6,38\%. Disponível em: http://g1.globo.com/economia/seu-dinheiro/noticia/2012/03/comprasem-real-no-exterior-tambem-tem-iof-de-638-diz-receita.html. Acesso em: 01jul. 2015.

${ }^{23}$ FOLLONI, André. Reflexões sobre complexity science no direito tributário. In: MACEI, Demetrius Nichele et. al. (coord.). Direito tributário e filosofia. Curitiba: Instituto Memória, 2014, p. 25.

${ }^{24}$ MORIN, Edgar. Introdução ao pensamento complexo. 4. ed. Porto Alegre: Sulina, 2011, p. 68.
} 
disciplina. Em realidade, busca-se estudar o que ficou de fora do conhecimento disciplinar, como conceitos inexplorados, relações impensadas no interior das disciplinas e o intento de interligar o que foi separado com as fronteiras dessas disciplinas. Em suma, a complexidade deve permanecer sempre aberta ao enfrentamento de novos problemas.

A análise do Direito, inclusive do Direito Tributário, sob o viés da complexidade, requer, dentre outras providências igualmente importantes, o estudo interdisciplinar. Essa interdisciplinaridade pode atingir os mais diversos graus. Dessa forma, a investigação pode percorrer diversos níveis de complexidade. 0 primeiro nível considera a relação de normas jurídicas entre si. 0 segundo, por seu turno, observa a relação entre vários ramos do direito. 0 terceiro nível de complexidade cuida de considerações acerca dos entrelaçamentos de ordenamentos jurídicos distintos, como direito comparado, etc. Já o quarto nível de complexidade defende o diálogo entre Direito e demais ramos científicos, como economia, política, etc. Nesse passo, o quinto nível relaciona direito com saberes racionais não científicos, como filosofia e ética. Por fim, o sexto e último nível de complexidade envolve direito com elementos estéticos, como o literário, o senso comum, o artístico. ${ }^{25}$

Sendo assim, a complexidade revela-se como alternativa ao pensamento redutor. A doutrina tributária reducionista, concentrando suas investigações jurídicas na norma jurídica, fica impossibilitada de enfrentar e de buscar soluções para problemas decorrentes da interação entre Direito Tributário e seu entorno. Dessas interações, como visto, comumente aparecem emergências não redutíveis a elementos ou a partes. Por isso, o estudo restrito ao aspecto normativo traz poucas perspectivas para a investigação de certos temas, tais como a ideia do que vem a ser o confisco e sua vedação constitucional, por exemplo: para estudá-lo, é preciso, para além das noções jurídicas, levar em consideração aspectos de cunho econômico. ${ }^{26}$

Fica, portanto, evidenciado que a adoção da perspectiva interdisciplinar se mostra fundamental para o desenvolvimento de uma ciência digna de ser chamada de complexa, algo que emerge como uma necessidade contemporânea tanto epistemológica quanto prática. A partir disso, este trabalho pretende trazer à colação breves apontamentos acerca do movimento teórico da Análise Econômica do Direito e da sua aplicação ao Direito Tributário.

\footnotetext{
${ }^{25}$ FOLLONI, André. Direito tributário, desenvolvimento e concorrência: o tratamento interdisciplinar e complexo de temas econômicos e jurídicos. In: FOLMANN, Melissa; GONÇALVES, Oksandro Osdival (org.). Tributação, concorrência e desenvolvimento. Curitiba: Juruá, 2013, p. 69-70.

${ }^{26}$ BORGES, José Souto Maior. Um ensaio interdisciplinar em Direito Tributário: superação da dogmática. Revista Dialética de Direito Tributário. São Paulo: n. 211, p. 106-121, abril/2013, p. 112.
} 


\section{ANÁLISE ECONÔMICA DO DIREITO: LINHAS GERAIS}

A Análise Econômica do Direito (AED), ou Law and Economics, em poucas palavras, é um movimento teórico que utiliza teorias econômicas e métodos econométricos para o exame de instituições jurídicas. $^{27}$ Trata-se de um AED um movimento por si só complexo, abrangendo diversas escolas, algumas divergentes entre si, como a Escola das Escolhas Públicas, a Escola de Chicago e a Escola da Nova Economia Institucionalista.

Nesse panorama, a Análise Econômica do Direito envolve sempre algum tipo de visão interdisciplinar que aplica ferramentas da Ciência Econômica ao estudo do Direito. A Economia fornece aos investigadores jurídicos diversas ferramentas científicas, tais como teoria dos preços, teoria dos jogos, teoria da escolha racional e assim por diante. O Direito, por exemplo, é definido principalmente em termos de sanções; já para os economistas, as sanções podem ser vistas como preços. ${ }^{28}$

Márcia Carla Ribeiro e Irineu Galeski Junior ${ }^{29}$ ressaltam o caráter interdisciplinar desse movimento, exatamente por trazer, para o interior do sistema de estudos jurídicos, conceitos como "valor", “utilidade" e "eficiência", na forma como são compreendidos nas ciências econômicas. Ainda, os juristas afirmam que a aplicação da AED pode se dar nos mais diversos ramos do Direito, desde aqueles mais evidentes, num primeiro plano, como é o caso do Direito da Concorrência e dos contratos mercantis, até setores jurídicos menos evidentes da aplicação desse movimento, tal como o Direito Penal e de Família.

Os estudos da AED podem se enquadrar, basicamente, em duas frentes, a saber: análise econômica normativa e análise econômica positiva. Na primeira, os estudos são realizados sob a lógica de auxiliar na criação de instrumentos jurídicos que tragam resultados mais eficientes com o menor custo possível. ${ }^{30}$ Por outro lado, na segunda, almeja-se avaliar o Direito e as suas instituições, tendo por base os efeitos que o ordenamento jurídico produz. Trata-se de indagar, por exemplo, dos impactos de uma decisão judicial sobre os agentes econômicos a ela

${ }^{27}$ CALIENDO, Paulo. Direito tributário e análise econômica do direito: uma visão crítica. Rio de Janeiro: Elsevier, 2009, p. 14.

${ }^{28}$ CARVALHO, Cristiano. A análise econômica do Direito Tributário. In: SCHOUERI, Luis Eduardo. (Coord.). Direito tributário: homenagem a Paulo de Barros Carvalho. São Paulo: Quartier Latin, 2008, p. 186.

${ }^{29}$ RIBEIRO, Márcia Carla; GALESKI JUNIOR, Irineu. Teoria geral dos contratos: contratos empresariais e análise econômica. 2. ed. rev. atual., e ampl. São Paulo: Editora Revista dos Tribunais, 2015, p. 83.

${ }^{30}$ CARVALHO, Cristiano. op. cit., p. 191. 
submetidos, se aquela decisão seria a mais acertada num determinado contexto econômico, se os efeitos pretendidos foram realmente alcançados e assim por diante. ${ }^{31}$

São três são as premissas para a aplicação da Análise Econômica do Direito. A primeira delas considera que os indivíduos são racionais, o que, no âmbito da AED, significa admitir que os sujeitos orientam as suas escolhas para a maximização dos seus interesses. E para tanto, esses indivíduos reagem a incentivos. Os agentes têm preferências completas e transitivas. Por exemplo, se um sujeito prefere " $A$ " a “ $B$ ", mas prefere " $B$ " a “ $C$ ", então prefere " $A$ " a " $C$ " ( $A>B$ e $B>C$, então, $A>C){ }^{32}$

Os indivíduos escolheriam, então, o objeto que melhor vier a atender ao requisito de utilidade: escolhe-se o objeto cujos benefícios superam os custos. ${ }^{33}$ Não é por outra razão que Richard Posner compreende a economia em função da busca pelo ser humano da maximização do seu interesse próprio. ${ }^{34}$ Assentir que os homens agem racionalmente não significa, contudo, que sejam racionais, de forma a elegerem opções mais acertadas no ponto de vista coletivo. ${ }^{35}$

Sob esses pressupostos, as pessoas reagiriam a normas jurídicas segundo uma lógica de incentivos. Ou seja, as normas jurídicas, principalmente as suas sanções, seriam processadas como preços pelos seus destinatários, como custo de realização de determinada conduta. Com isso, ao identificar-se a sanção na perspectiva de preços, os indivíduos, considerados racionais, pautam as suas condutas conforme os custos e os benefícios que as sanções acarreterão. ${ }^{36}$

A segunda premissa da Análise Econômica do Direito diz respeito ao equilíbrio. Admite-se que os agentes atuam de forma racional, mas suas atuações tendem ao equilíbrio porque num determinado momento as atuações individuais não influenciam o mercado mais do que outras ações. ${ }^{37}$ Atingir-se-ia um padrão comportamental equilibrado, uma vez que, como os agentes atuam de modo a maximizar os seus interesses, surgiriam padrões interativos estáveis sugestivos de maneira tal que os indivíduos pudessem responder a incentivos. ${ }^{38}$

31 FORTES, Fellipe Cianca; BASSOLI, Marlene Kempfer. Análise econômica do direito tributário: livre iniciativa, livre concorrência e neutralidade fiscal. Scientia luris, Londrina, v. 14, p. 235-253, nov. 2010, p. 237.

32 CARVALHO, Cristiano. A análise econômica do Direito Tributário. In: SCHOUERI, Luis Eduardo. (Coord.). Direito tributário: homenagem a Paulo de Barros Carvalho. São Paulo: Quartier Latin, 2008, p. $187-188$.

${ }_{33}$ RIBEIRO, Márcia Carla; GALESKI JUNIOR, Irineu. Teoria geral dos contratos: contratos empresariais e análise econômica. 2. ed. rev. atual., e ampl. São Paulo: Editora Revista dos Tribunais, 2015, p. 96.

34 POSNER, Richard A. El análisis económico del derecho. 2. ed. México: FCE, 2007, p. 25.

${ }^{35}$ RIBEIRO, Márcia Carla; GALESKI JUNIOR, Irineu. op. cit., p. 96.

${ }^{36}$ GONÇALVES, Oksandro Osdival; RIBEIRO, Marcelo Miranda. Incentivos Fiscais: uma perspectiva da Análise Econômica do Direito. EALR, V. 4, n 1, p. 79-102, jan./jun. 2013, p. 82-83.

${ }^{37}$ CARVALHO, Cristiano. op. cit., p. 189.

${ }^{38}$ GONÇALVES, Oksandro Osdival; RIBEIRO, Marcelo Miranda. op. cit., p. 83. 
A terceira e última premissa da AED está relacionada com a eficiência. Ela deve levar em consideração a perspectiva de que as necessidades são sempre crescentes, ao passo em que os recursos são escassos. ${ }^{39}$ Segundo Richard Posner, os recursos são melhor aproveitados se transacionados em mercado. Evidentemente, nem tudo pode ser tratado na lógica da eficiência, que despreza outros valores. ${ }^{40}$ É uma análise parcial. Contudo, dentro dos seus limites, possível. Existem barreiras para as transações no mercado, tais como externalidades, altos custos de informações, etc. ${ }^{41}$ Essas falhas de mercado devem ser combatidas pelas regras jurídicas. A título exemplificativo, existem os custos de transação, os quais se referem aos dispêndios necessários para se efetivar e fazer cumprir uma obrigação (são exemplos: custo de advogados, do aclaramento judicial de cláusulas de um contrato e outros). Havendo custos de transações consideráveis, compete ao Estado intervir juridicamente, a fim de garantir a eficiência econômica. ${ }^{42}$

Em suma, a Análise Econômica do Direito, cujas premissas são a escolha racional, equilíbrio e eficiência, pode permitir complexificar a compreensão do Direito a partir de conceitos derivados da Ciência Econômica.

\section{ANÁLISE ECONÔMICA DO DIREITO APLICADA AO DIREITO TRIBUTÁRIO}

Deve-se, agora, verificar as possibilidades de aplicação da Análise Econômica do Direito no campo do Direito Tributário e os frutos que essa perspectiva de estudo pode trazer aos tributaristas.

Paulo Caliendo ${ }^{43}$ recorda que nenhuma economia pode funcionar sem uma mínima base institucional, a qual tem custos que precisam de ser financiados. Da mesma forma, Cristiano Carvalho $^{44}$ expõe que é impossível eliminar por completo a tributação, dado que mantém o

\footnotetext{
${ }^{39}$ RIBEIRO, Márcia Carla; GALESKI JUNIOR, Irineu. op. cit., p. 100-101.

${ }^{40}$ Ibid., p. 134-135.

${ }^{41}$ POSNER, Richard A. El análisis económico del derecho. 2. ed. México: FCE, 2007, p. 34.

42 RIBEIRO, Márcia Carla; GALESKI JUNIOR, Irineu. Teoria geral dos contratos: contratos empresariais e análise econômica. 2. ed. rev. atual., e ampl. São Paulo: Editora Revista dos Tribunais, 2015, p. 121 e 125.

${ }^{43}$ CALIENDO, Paulo. Direito tributário e análise econômica do direito: uma visão crítica. Rio de Janeiro: Elsevier, 2009, p. 17.

${ }^{44}$ CARVALHO, Cristiano. A análise econômica do Direito Tributário. In: SCHOUERI, Luis Eduardo. (Coord.). Direito tributário: homenagem a Paulo de Barros Carvalho. São Paulo: Quartier Latin, 2008, p. 194.
} 
Estado, o qual está incumbido de proteger os direitos individuais, a que se deve acrescer a promoção de direitos sociais.

O que não é admissível, entretanto, é a inviabilização das atividades econômicas em razão da exação. Por isso, sobreleva destacar a ideia de eficiência econômica aplicável à tributação. É dizer, trata-se dos limites da tributação como forma de viabilizar as atividades privadas. $^{45}$

Dentre as várias contribuições que a Economia pode oferecer está a ideia de tributação entendida a partir da teoria dos custos de transação. Esses custos podem ser considerados em sentido estrito, ou seja, o tributo pago é considerado um custo para a efetivação de um negócio jurídico (se uma mercadoria custa $\mathrm{R} \$ 1.000,00$ e o imposto incidente sobre a operação de circulação é de $10 \%$ do valor da mercadoria, esta é transacionada pelo valor de $\mathrm{R} \$ 1.100,00$, cujo custo adicional é de $\mathrm{R} \$ 100,00$, decorrente da exação). ${ }^{46}$ Porém, em sentido amplo, a tributação como custo de transação é considerada na utilização dos mecanismos de mercado. Por exemplo, o recolhimento de imposto sobre as vendas (sales taxes) pode dirigir a organização das empresas de maneira tal que incentive a concentração das operações internas, com o escopo de evitar a incidência da referida exação. ${ }^{47} \mathrm{Em}$ muitas situações, o tributo pode ser considerado como sendo custos de transação em sentido amplo, pois carrega consigo realidades como insegurança jurídica, sonegação; burocracia fiscal, incentivos fiscais e a aplicação de penalidades. ${ }^{48}$

Em situações de normalidade, tributos já são considerados custos de transação, pois influenciam os agentes econômicos no momento de tomar decisões acerca de estratégias empresariais. Por exemplo, decisões a respeito de em que Estado instalar a planta produtiva (em relação ao ICMS), a transferência da sede para outro Município (no tocante ao ISS), a divisão da produção para auferir benefícios fiscais (remetendo parte do processo produtivo para a Zona Franca de Manaus), e assim por diante. Dessa forma, a AED auxilia na compreensão das relações existentes entre as normas e os custos de transação, com o fito de reduzi-los ao máximo, uma vez que é impossível anulá-los. Se um tributo distorce a concorrência, além de ser por si só um

\footnotetext{
${ }^{45} \mathrm{Id}$.

${ }^{46}$ CALIENDO, Paulo. Direito tributário e análise econômica do direito: uma visão crítica. Rio de Janeiro: Elsevier, 2009, p. 22.

47 Ibid., p. 22-23.

48 lbid., p. 23.
} 


\section{每

custo de transação, deve ser reputado como falha de mercado a ser sanada. ${ }^{49}$ A Análise Econômica pode evidenciar esse fato.

Adiante, a título de exemplos, serão expostos alguns casos bem comuns na prática tributária e que podem ser analisados sob a perspectiva da AED, mormente sob o viés da teoria dos custos de transação.

\subsection{Questões tributárias suscetíveis de exame a luz da AED}

\subsubsection{Obrigações acessórias}

O sistema tributário não se resume a tributos. Ao lado deles, existem as obrigações acessórias, consistentes nos deveres de fazer e não fazer, suportados pelos cidadãos, em favor da fiscalização tributária. Essas obrigações são, de alguma forma, relacionadas às atividades de fiscalização e arrecadação tributárias. São exemplos de obrigações acessórias a emissão de notas fiscais, a escrituração de livros fiscais, declarações de todas as espécies (DCTF, DIRF, GIA) etc.. ${ }^{50}$

O cumprimento dessas obrigações acessórias acarreta custos elevados. São os chamados "custos de conformidade". O Brasil é campeão mundial nesses custos. No nosso país, é preciso de 2600 horas anuais para cumprir as obrigações tributárias, volume que nos rende o primeiro lugar no ranking dos países mais demorados e difíceis para o cumprimento de obrigações fiscais, segundo o relatório do Doing Business, feito pelo Banco Mundial em 2007. ${ }^{51}$

Como resultado, esses custos de conformidade refletem-se em pesados custos de transação, impactando negativamente no mercado e no custo final do consumo, independentemente do padrão de vida do consumidor e de sua capacidade contributiva. Além disso, essa situação, dificultando a iniciativa econômica, pode ser vista como contrária a relevantes preceitos constitucionais, visto que livre iniciativa é um dos princípios da ordem econômica. ${ }^{52}$

\subsubsection{Incentivos fiscais}

${ }^{49}$ GONÇALVES, Oksandro Osdival; GONÇALVES, Helena de Toledo Coelho. Tributação, concorrência e desenvolvimento econômico sustentável. In: FOLMANN, Melissa; GONÇALVES, Oksandro Osdival (Coords.). Tributação, concorrência e desenvolvimento. Curitiba: Juruá, 2013, p. 25.

${ }^{50}$ CARVALHO, Cristiano. A análise econômica do Direito Tributário. In: SCHOUERI, Luis Eduardo. (Coord.). Direito tributário: homenagem a Paulo de Barros Carvalho. São Paulo: Quartier Latin, 2008, p. 201.

${ }^{51}$ Id.

52 Ibid., p. 203. 
Uma vez que o tributo, sob o ponto de vista econômico, é um custo de transação, a decisão do empreendedor em instalar ou não o empreendimento numa determinada localidade ou de acordo com determinados processos produtivos, por exemplo, leva em consideração a existência de incentivos ficais. ${ }^{53}$ Esses incentivos fiscais assumem, sob o ponto de vista jurídico, as mais diversas roupagens: isenções, reduções de alíquotas e/ou bases de cálculo, anistia, moratória, remissão, concessão de créditos tributários, diferimento do pagamento de tributos, créditos presumidos, alíquotas zero, entre outros. ${ }^{54}$ Sob o ponto de vista econômico, contudo, são idênticos no fato de consistirem num alívio de custo de transação.

Por que implicam diferenciação entre contribuintes, os incentivos fiscais apenas devem ser concedidos nas hipóteses de combate a problemas econômicos, sociais, desigualdades regionais e outros com amparo constitucional, respeitado o postulado da proporcionalidade. Ademais, é imprescindível a indicação dos seus beneficiários, os motivos da concessão, as condições de fruição, o prazo de vigência e o montante de benefícios concedidos. 0 Poder Público, após conceder os incentivos ficais, deve efetivamente fiscalizar se estão sendo aplicados em favor do atendimento dos fins para os quais foram concedidos. ${ }^{55}$

No cenário atual, Maria de Fátima Ribeiro ${ }^{56}$ assevera que muitos incentivos fiscais são concedidos em afronta ao pacto federativo, violando a Lei de Responsabilidade Fiscal e estimulando a guerra fiscal entre os entes da Federação. No caso de incentivos fiscais relativos ao ICMS, por exemplo, a Lei Complementar n. 24/1975 estipula que estes somente podem ser concedidos mediante convênio firmado pelos integrantes do Conselho Nacional de Política Fazendária (CONFAZ). Convênios dessa espécie, ainda conforme a lei complementar, apenas se materializam se a unanimidade dos membros do conselho - representantes dos Estados e do Distrito Federal ligados às respectivas pastas da Fazenda - acordarem nesse sentido. ${ }^{57}$

Por ocasião do Processo Administrativo $n^{\circ}$ 038/99, o Plenário do CADE apreciou uma consulta formulada pelo Pensamento Nacional das Bases Empresariais (PNBE) envolvendo

\footnotetext{
${ }^{53}$ GONÇALVES, Oksandro Osdival; RIBEIRO, Marcelo Miranda. Incentivos Fiscais: uma perspectiva da Análise Econômica do Direito. EALR, V. 4, n 1, p. 79-102, jan./jun. 2013, p. 85.

${ }^{54}$ Ibid., p. 91.

${ }^{55}$ GONÇALVES, Oksandro Osdival; RIBEIRO, Marcelo Miranda. Incentivos Fiscais: uma perspectiva da Análise Econômica do Direito. EALR, V. 4, n 1, p. 79-102, jan./jun. 2013, p. 91.

56 RIBEIRO, Maria de Fátima. Reflexos da Tributação no Desequilíbrio da livre Concorrência. In: GRUPENMACHER, Betina Treiger; CAVALCANTE, Denise Lucena; RIBEIRO, Maria de Fátima; QUEIROZ, Mary Elbe. Novos horizontes da tributação: um diálogo luso-brasileiro. Coimbra: Almedina, 2012, p. 242-243.

${ }^{57}$ CARRAZZA, Roque Antonio. ICMS. 16. ed. rev., e atual. São Paulo: Malheiros, 2012, p. 580.
} 
incentivos fiscais concedidos pelos Estados-Membros e violação à livre iniciativa e concorrência. A consulta cotejou o impacto da redução do ICMS sobre o lucro das empresas do setor de sabonetes. A partir do estudo, restou demonstrado que a variação do lucro das empresas chega a $388 \%$ das empresas beneficiadas com alíquota $0 \%$, em comparação com as empresas que recolhem $18 \%$ a título de ICMS. ${ }^{58}$

Nessa perspectiva, a concessão de incentivos fiscais pode contribuir para o alcance de margens de lucro muito superiores para os agraciados pelos benefícios. Ademais, isso faz com que, muitas vezes, uma empresa se instale num local onde os custos sejam muito altos, sob a condição de que os incentivos compensem a diferença. Disso decorre uma perda de eficiência, dado que os recursos são consumidos em grau superior ao necessário. ${ }^{59}$

Portanto, os incentivos fiscais fazem parte importante do cálculo dos custos de transação no momento do agente econômico instalar ou levar adiante o seu empreendimento. Contudo, o modo como esses benefícios são distribuídos pode conduzir a perdas relevantes de eficiência na aplicação dos recursos, além de, eventualmente, prejudicarem a livre iniciativa e a livre concorrência.

\section{ANÁLISE ECONÔMICA DO DIREITO: LIMITES E POSSIBILIDADES PARA A CONSTRUÇÃO DE UMA CIÊNCIA COMPLEXA}

As considerações acerca das possibilidades de aplicação de Análise Econômica do Direito ao Direito Tributário mostram algumas interessantes potencialidades desse estudo interdisciplinar. Faz parte do contexto contemporâneo, no qual os tributaristas precisam de se abrir a novos saberes, se desejam resolver os problemas que se apresentam e, para tanto, compreender temas que relacionam Direito Tributário com o desenvolvimento e a livre concorrência. Em realidade, cuida-se de contribuir para a análise do que ficou na fronteira entre as disciplinas: Direito Tributário, Direito Econômico e Economia. ${ }^{60}$

\footnotetext{
${ }^{58}$ GONÇALVES, Oksandro Osdival; RIBEIRO, Marcelo Miranda. op. cit., p. 97-98.

${ }^{59}$ GONÇALVES, Oksandro Osdival; RIBEIRO, Marcelo Miranda. Incentivos Fiscais: uma perspectiva da Análise Econômica do Direito. EALR, V. 4, n 1, p. 79-102, jan./jun. 2013, p. 99.

${ }^{60}$ FOLLONI, André. Direito tributário, desenvolvimento e concorrência: o tratamento interdisciplinar e complexo de temas econômicos e jurídicos. In: FOLMANN, Melissa; GONÇALVES, Oksandro Osdival (org.). Tributação, concorrência e desenvolvimento. Curitiba: Juruá, 2013, p. 68.
} 
Esse estudo interdisciplinar não rompe com os limites existentes entre as disciplinas. Direito Tributário não se torna Economia, nem se confunde com ela. Contudo, não mais se olvidam as inter-relações travadas entre o Direito Tributário e a Economia. Realiza-se, dessa forma, um estudo interdisciplinar num quarto nível de complexidade. A aproximação entre Direito e Economia, não obstante esta disciplina seja considerada, normalmente, como não jurídica e inapreensível pelo jurista, viabiliza a investigação de determinados problemas jurídico-tributários concretos.

Nesse contexto, a Análise Econômica do Direito promove o estudo interdisciplinar entre Direito e Economia, ainda que apenas parcial. Paulo Caliendo indica alguns dos méritos desse tipo de exame: i) o Direito não pode ser considerado de forma autônoma, em face da realidade social e econômica; ii) abordagem a partir de métodos presentes em outras ciências, tais como economia e filosofia; iii) critica à interpretação do direito que não leva em conta aspectos da vida econômica e social. ${ }^{61}$ Ainda, o mesmo jurista aduz que a, AED aplicada no Direito Tributário, auxilia na busca de respostas a perguntas econômica e juridicamente legítimas, quais sejam: como as normas tributárias interferem na decisão dos agentes econômicos? Como as normas econômicas se refletem na distribuição e produção de riquezas? É legítima e possível a construção de um sistema tributário eficiente, que visa a construção de um mercado mais adequado diante dos imperativos de justiça social? ${ }^{62}$

Assim, a Análise Econômica do Direito apresenta-se como uma ferramenta útil a contribuir com a construção de uma Ciência do Direito Tributário complexa. Mesmo assim, é preciso advertir que a AED é apenas uma ferramenta, ou seja, não é a única, nem mesmo é suficiente para esgotar a complexidade das relações entre os fenômenos jurídico-tributários e econômicos. Isso porque muitas relações nas quais o Direito Tributário se envolve não são levadas em conta pela AED, que sequer as pretende considerar.

Basta verificar a ideia de níveis de complexidade. A complexidade pode ser averiguada, além do quarto, também quinto nível, por meio das inter-relações com saberes racionais não necessariamente científicos (Filosofia, Ética etc.) e em sexto grau, mediante conhecimentos de cunho estético (Literatura, Artes etc.). ${ }^{63}$ Os estudos da Análise Econômica do Direito estancam

\footnotetext{
${ }^{61}$ CALIENDO, Paulo. Direito tributário e análise econômica do direito: uma visão crítica. Rio de Janeiro: Elsevier, 2009, p. 13.

62 Ibid., p. 12.

63 FOLLONI, André. Direito tributário, desenvolvimento e concorrência: o tratamento interdisciplinar e complexo de temas econômicos e jurídicos. In: FOLMANN, Melissa; GONÇALVES, Oksandro Osdival (org.). Tributação, concorrência e desenvolvimento. Curitiba: Juruá, 2013, p. 69.
} 
no quarto grau de complexidade. Até mesmo dentro do quarto grau de complexidade a AED não abarca outras influencias caras ao Direito Tributário, como as psciológicas, sociológicas e pedagógicas e outras. Então, é um instrumento útil, embora limitado como, provavelmente, qualquer outro. Isso, por si só, não desmerece a Análise Econômica do Direito, que não se presta a esgotar a complexidade dos possíveis objetos de estudo do tributarista. Até porque é inerente ao estudo da complexidade, ao menos nos padrões atuais, a impossibilidade do alcance da completude. Encontrar a completude de compreensão da complexidade soa como uma contradição em termos.

Em conclusão, a Análise Econômica do Direito, embora não esgote todas as perspectivas de estudo aplicáveis ao Direito Tributário, pode contribuir de maneira interessante para a construção de uma Ciência Complexa.

\section{CONCLUSÃO}

A Ciência do Direito Tributário reducionista, preocupada exclusivamente com a análise das normas tributárias, é justificável dentro do contexto em que surgiu: um ambiente no qual a doutrina tributária era escassa, assim como o arranjo de normas tributárias era fundamentalmente caótico. Inclusive, é justificável pelo contexto político em que surgiu, um período da ditadura militar no qual os estudos tributários dificilmente poderiam discorrer sobre aspectos mais afetos à substancialidade ou à justiça da tributação.

Embora seja compreensível que o intento da doutrina nos tempos iniciais fosse de proceder a estudos voltados para normas tributárias, com o fito de reduzir as dificuldades existentes para compreender a tributação nacional, hoje essa perspectiva não mais se pode sustentar como a única metodologicamente possível ao estudioso do Direito Tributário. É simplesmente incorreto ignorar as interações entre o Direito Tributário e o seu meio e como influencia, muitas vezes decididamente, nos variados segmentos da vida social.

Uma ciência complexa não deve ignorar essas relações. Um traço marcante das ciências complexas é a interdisciplinaridade. Uma ciência, para ser considerada complexa, precisa de estar aberta a outros saberes.

No caso do Direito Tributário, uma possibilidade que se apresenta ao pesquisador contemporâneo é o uso dos instrumentais teóricos e analíticos da Análise Econômica do Direito (AED). Trata-se de um movimento pelo qual se utilizam ferramentas da Economia para 
compreender e examinar questões jurídicas. Considerando que a Análise Econômica do Direito tem por premissas a escolha racional, equilíbrio e eficiência, demonstramos sua aplicabilidade para a análise de situações comuns na vida do tributarista: obrigações acessórias e incentivos fiscais. Esses exemplos foram apresentados segundo a ideia econômica de custos de transação.

Sendo assim, a Análise Econômica do Direito, mesmo não abarcando todas as condicionantes que influenciam o sistema jurídico, tem utilidade para o desenvolvimento das ciências jurídico-tributárias complexas, haja vista que promove estudos interdisciplinares envolvendo Direito Tributário e Economia, trabalhando no quarto nível de complexidade.

\section{REFERÊNCIAS}

ATALIBA, Geraldo. Hipótese de incidência tributária. 6. ed. São Paulo: Malheiros Editores, 2013.

ÁVILA, Humberto. A doutrina e o Direito Tributário. In: ÁVILA, Humberto (org.). Fundamentos do direito tributário. Madrid: Marcial Pons, 2012.

BECKER, Alfredo Augusto. Carnaval Tributário. 2. ed. São Paulo: LEJUS, 1999.

BORGES, José Souto Maior. Um ensaio interdisciplinar em Direito Tributário: superação da dogmática. Revista Dialética de Direito Tributário n² 211. São Paulo: Dialética, 2013.

BYRNE, David. Complexity Theory and the Social Sciences: an introduction. London: Routledge 1998.

CALIENDO, Paulo. Direito tributário e análise econômica do direito: uma visão crítica. Rio de Janeiro: Elsevier, 2009.

CARRAZZA, Roque Antonio. ICMS. 16. ed. rev., e atual. São Paulo: Malheiros Editores, 2012.

CARVALHO, Cristiano. A análise econômica do Direito Tributário. In: SCHOUERI, Luis Eduardo. (coord.). Direito tributário: homenagem a Paulo de Barros Carvalho. São Paulo: Quartier Latin, 2008.

CARVALHO, Paulo de Barros. Curso de direito tributário. 25. ed. São Paulo: Saraiva, 2013.

FOLLONI, André. Direito tributário, desenvolvimento e concorrência: o tratamento

interdisciplinar e complexo de temas econômicos e jurídicos. In: FOLMANN, Melissa; GONÇALVES, Oksandro Osdival (org.). Tributação, concorrência e desenvolvimento. Curitiba: Juruá, 2013.

, André. O papel do direito tributário no desenvolvimento nacional. In: Anais do XXIII

Encontro Nacional do CONPEDI. Disponível em:

http://www.publicadireito.com.br/artigos/?cod=20dd77ae36c56353. Acesso em: 10 set. 2014. 
, André. Reflexões sobre complexity science no direito tributário. In: MACEI, Demetrius Nichele et. al. (coord.). Direito tributário e filosofia. Curitiba: Instituto Memória, 2014.

FORTES, Fellipe Cianca; BASSOLI, Marlene Kempfer. Análise econômica do direito tributário: livre iniciativa, livre concorrência e neutralidade fiscal. Scientia luris, Londrina, v. 14, p. 235253, nov. 2010.

GOLDSTEIN, Jeffrey. Emergence as a construct: history and issues. Emergence. v. 1, n. 1, p. 4977, 1999.

GONÇALVES, Oksandro Osdival; GONÇALVES, Helena de Toledo Coelho. Tributação, concorrência e desenvolvimento econômico sustentável. In: FOLMANN, Melissa; GONÇALVES, Oksandro Osdival (coords.). Tributação, concorrência e desenvolvimento. Curitiba: Juruá, 2013.

Oksandro Osdival; RIBEIRO, Marcelo Miranda. Incentivos Fiscais: uma perspectiva da Análise Econômica do Direito. In: EALR, V. 4, n 1, p. 79-102, jan./jun. 2013.

GRECO, Marco Aurélio. Crise do formalismo no direito tributário brasileiro. Revista da PGFN. 2011. Disponível em: http://www.pgfn.fazenda.gov.br/revista-pgfn/revista-pgfn/ano-i-numeroi/greco.pdf. Acesso em: 01jul.2015.

JÖRG, Ton. New thinking in complexity for the social sciences and humanities: a generative, transdisciplinary approach. New York: Springer, 2011, p. 43-84.

MARTELLO, Alexandro. G1. Brasília, 06 mar. 2012. Gastos com cartão de crédito em reais no exterior têm IOF de 6,38\%. Disponível em: http://g1.globo.com/economia/seu-

dinheiro/noticia/2012/03/compras-em-real-no-exterior-tambem-tem-iof-de-638-diz-

receita.html. Acesso em: 01jul. 2015.

MOREIRA, André Mendes; MACHADO, Sophia Goreti Rocha. Conceito de tributo e sua divisão em espécies. In: GRUPENMACHER, betina Treiger (Coord.). Tributação: democracia e liberdade: em homenagem à Ministra Denise Martins Arruda. São Paulo: Noeses, 2014.

MORIN, Edgar. Introdução ao pensamento complexo. 4. ed. Porto Alegre: Sulina, 2011.

, Edgar. O desafio da complexidade. In: Ciência com consciência. Tradução de Maria D. Alexandre e Maria Alice Sampaio Dória. Rio de Janeiro: Bertrand Brasil, 1996, p. 175-193.

POSNER, Richard A. El análisis económico del derecho. 2. ed. México: FCE, 2007.

RIBEIRO, Márcia Carla; GALESKI JUNIOR, Irineu. Teoria geral dos contratos: contratos empresariais e análise econômica. 2. ed. rev. atual., e ampl. São Paulo: Revista dos Tribunais, 2015.

RIBEIRO, Maria de Fátima. Reflexos da Tributação no Desequilíbrio da livre Concorrência. In: GRUPENMACHER, Betina Treiger; CAVALCANTE, Denise Lucena; RIBEIRO, Maria de Fátima; QUEIROZ, Mary Elbe. Novos horizontes da tributação: um diálogo luso-brasileiro. Coimbra: Almedina, 2012. 
ISSN 1981-3694

(DOI): $10.5902 / 1981369419726$ REVISTA ELETRÔNICA DO CURSD DE

VIEIRA, José Roberto. Imposto sobre Produtos Industrializados: uma águia garciamarquiana entre os tributos. In: SANTI, Eurico Marcos Diniz de; ZILVETI, Fernando Aurélio; MOSQUERA, Roberto Quiroga (coords.). Tributação das Empresas. São Paulo: Quartier Latin, 2006.

Recebido em: 30.09.2015 / Revisões requeridas em: 17.03.2016 / Aprovado em: 24.03.2016 